\title{
SMART SYSTEMS AND SIMPLE AGENTS: Industry Pricing by Parallel Rules
}

\author{
Raymond Board and P. A. Tinsley*
}

Version: December 1996

\begin{abstract}
A standard macroeconomic specification is that the aggregate economy is directed by a single, smart representative agent using optimal decision rules. This paper explores an alternative conjecture that the dynamic behavior of markets is often better interpreted as the interactions of many heterogeneous, rule-of-thumb agents who are loosely-coupled in smart systems-much like the contrast of a single serial processor with global information versus parallel processors with limited communications. The illustration used in this paper is the contrast between a conventional macro model of sluggish adjustments in an aggregate producer price index and a model of delayed industry price adjustments in a distributed production system under costly inter-firm communications.
\end{abstract}

Keywords: Costly communications; parallel Jacobi solutions; producer pricing.

*Author addresses are: Federal Reserve Board, Washington, DC 20551, rboard@frb.gov and ptinsley@frb.gov. A variant of this paper appears in Gilli (1996). Views expressed in this paper are those of the authors and do not necessarily represent those of the Board of Governors of the Federal Reserve System or its staff. 


\section{Introduction}

Dynamic first-order conditions, such as Euler equations, are useful abstractions in econometric modeling to motivate distributed lag responses to unanticipated shocks. However, the assumption that sectoral aggregates or entire economies may be viewed "as if" they are directed by a single, omniscient representative agent, who is subjected to costs of adjusting actions, is an uncomfortable metaphor for macroeconomics. This is especially so in dynamic analysis of aggregate prices where not only the allocative role of prices is blurred by aggregation but significant direct costs of adjusting prices are hard to identify.

The effect of transforming the "invisible hand" into the "representative agent" is to replace system conditions for survival and inter-agent communication with the decision rules of a single, optimizing agent. A standard rationale for single-agent modeling is that profit-maximizing agents drive out all inferior strategies, and the dominant strategy is easily learned by all agents when shared in a simple feedback format. Objections to this Darwinian assertion of the approximate homogeneity of surviving strategies include everyday observations of heterogeneous behavior and examples in biology of the "brittleness" of systems with over-specialized genetic traits.

An intriguing alternative modeling design is suggested by the "zero-intelligence" agents of Becker (1962) and Gode and Sunder (1993) where local constraints, such as static or dynamic budget constraints, can cause random micro behavior to produce rational system results, such as downward-sloping aggregate demand schedules and efficient pricing in auction markets.

The analogous "smart system" conjecture explored in this paper is that parallel solution implementations of optimization algorithms often require only local information for each parallel processor, but the system solution is the same as that reached by a serial processor with global information. Parallel Jacobi iterative solution of a linear equation system, such as $B x-b=0$, appears to be a powerful example of this conjecture because solution of a system of linearized first-order conditions is the essential core of optimizations ranging from nonlinear searches of likelihood functions to companion systems of multivariate Euler equations. In the case of Jacobi solutions of the linear equation system, a number of accelerated methods exist for specialized structures of the $B$ matrix. The case where $B$ is nearly-decomposable into diagonal blocks is notable because global inversion of $B$ is nearly achieved by independent inversions of the diagonal blocks. Unfortunately, if the dimensions of $B$ are sizable, it is very hard to determine the best near-block patterns in $B{ }^{1}$

Producer pricing in a distributed production system is used to demonstrate the weak local information requirements of Jacobi algorithms. The relative sparseness of the US input-output system at the six-digit level of aggregation illustrates the contrast between aggregate information

\footnotetext{
${ }^{1}$ Notable exceptions are the patterns of banded matrices associated with boundary-value problems of dynamic systems; vid. Stoer and Bulirsch (1980) and Fisher, Holly, and Hughes-Hallett (1986).
} 
and the industry-specific information that is required to maintain margins between revenues and costs in each industry. Sensible rules-of-thumb, such as sharing information with direct suppliers and customers, are shown to accelerate adjustment to equilibrium.

\section{Producer Price Adjustments}

Deep divisions exist in macroeconomics regarding the dynamic adjustments of prices. In classical theories, markets are continuously cleared by flexible prices, including instantaneous adjustments of nominal prices to agents' perceptions of monetary policy. In contrast, Keynesian theories suggest non-auction prices are slow to adjust to equilibrium, and short-run clearing is achieved by changes in transacted quantities.

These theories are more than of academic interest, in part, due to differing implications for monetary policy. In classical models, inflation inertia is due only to anticipations of persistent inflationary policies, and costs of policy disinflations are negligible. In archetypal Keynesian models, announcement effects of policy are generally dominated by prolonged real effects of interest rates and bank credit, and disinflations are initiated by reducing the growth of real activity.

A sufficient reason for the continuing existence of such disparate theories is that neither side is able to fully account for several stylized facts regarding actual price dynamics and so each can claim a measure of empirical relevance.

There are three major stylized facts about producer price dynamics that a general theory of producer pricing must explain: ${ }^{2}$

- Prices of manufactured goods are sticky. As shown later, the mean lag response of US manufacturing prices to unanticipated shocks is about nine months.

- Producer prices are adjusted infrequently. Although there are few systematic analyses of this characteristic, available estimates suggest that a typical U.S. producer price may be altered no more frequently than once a year. ${ }^{3}$

- Adjustments of producer prices in inflationary episodes can be large and rapid. In a study of European hyperinflations after WWI, Sargent (1982) indicates that producer prices in Germany increased on the order of $10^{7}$ in the twelve-month interval, June 1923 - June 1924.

Although there are a number of theories of sticky nominal price adjustments, ranging from explicit costs of adjusting prices, Rotemberg (1982), to instrument uncertainty, Greenwald and Stiglitz (1989), none appear capable of explaining the stylized facts listed above - where nominal

\footnotetext{
${ }^{2}$ Additional macro and micro stylized facts regarding prices may be found in Gordon (1981, 1990) and Schmalensee (1989), respectively.

${ }^{3}$ In analyzing the Stigler-Kindahl data, Carlton (1986) reports an average adjustment frequency of about once a year. Similarly, over half of the firms interviewed by Blinder (1991) indicated prices were not adjusted for a year or longer. Of course, infrequent price adjustments may be sufficiently large so that staggered price changes at the micro level may be consistent with prompt responses of aggregate price indexes, cf. Caplin and Spulbur (1987).
} 
prices are sometimes adjusted rapidly and at other times appear to be not well-connected to current market conditions.

After a brief review of a generic adjustment cost model of producer pricing and empirical estimates of selected characteristics of producer price adjustments, the remainder of this paper pursues a very different interpretation of dynamic price movements. An alternative to explicit adjustment costs is that sluggish price movements are due to lags in obtaining relevant information in a distributed production system. The consequent adjustment lags are not easily categorized as signal extraction or learning by a representative agent but are rather a result of system interactions among heterogeneous agents using reasonable rules-of-thumb to set margins between costs and revenues. Although the disaggregated pricing model is an extreme abstraction of information processing by real producers, it provides at least a benchmark of dynamic consequences of using affordable solution algorithms in a complex environment.

\subsection{Models of the dynamic adjustment of manufacturing prices.}

The pricing of a standardized product by an industry with $s$ identical producers may be represented by

$$
p^{*}=m+c,
$$

where $p^{*}$ denotes the log of the optimal or "target" price, $m$ is the log markup by producers, and $c$ is the log of marginal cost. Ignoring strategic considerations, the markup is

$$
m=\log \left(\frac{1}{1-\frac{1}{s \eta}}\right)
$$

where $\eta$ is the price elasticity of demand, and (2) displays the monopoly and competitive solutions as either $s \rightarrow 1$ or $s \rightarrow \infty$.

Gross production is Cobb-Douglas in both purchased materials and rented services of primary factors. Also, returns to scale are constant so that the log of marginal cost is proportional to the weighted average of log input prices

$$
c \propto \theta_{1} p_{1}+\cdots+\theta_{m} p_{m}+\left(1-\sum_{i} \theta_{i}\right) v
$$

where $\theta_{i}$ and $p_{i}$ are the cost share and $\log$ price of the $i$ th materials input, and $v$ denotes the $\log$ unit price of value-added by the producing industry.

Now suppose the actual price is displaced from the target price, perhaps due to errors in estimating current cost or demand elasticity, but a cost is incurred in adjusting price from its current level. A tractable model of price dynamic adjustment is presented by Rotemberg (1982) where 
producers are assumed to minimize the discounted sum of the square of the distance between the price and the moving target price and the cost of squared changes in the level of the price. The required equation of motion for the price is the familiar second-order Euler equation

$$
E_{t}\left\{A(L) A(B F) p_{t}-A(1) A(B) p_{t}^{*}\right\}=0
$$

where $E_{t}\{$.$\} denotes the expectation given information through t-1 ; A(L)$ is a first-order polynomial in the lag operator $L ; A(L)=(1-\lambda L) ; F$ is the lead operator; and $B$ is a (quarterly) discount factor.

To obtain a benchmark estimate of the mean adjustment lag of producer prices, let $p$ denote the $\log$ of the price of U.S. manufacturing goods. Producer prices are generally difference-stationary, containing one unit root. This, in turn, permits two empirical simplifications. First, the target gap or log distance between the current price and target price can be established by a cointegration regression in the log levels

$$
\begin{aligned}
p_{t} & =\beta \vec{x}_{t}+\epsilon_{t}, \\
& =p_{t}^{*}+\left(p_{t}-p_{t}^{*}\right),
\end{aligned}
$$

where $\vec{x}_{t}$ is a vector of the arguments of the target price as defined above, including the prices of non-manufacturing inputs, the wage rate, and trend rate of labor productivity. Note that the cointegrating discrepancy is an estimate of the price "gap" or distance to the target price trend.

Also, using the fact that both $p$ and $p^{*}$ are $\mathrm{I}(1)$, the decision rule for $p$ can be expressed in a "rational" error-correction format as

$$
\Delta p_{t}=-(1-\lambda)\left(p_{t-1}-p_{t-1}^{*}\right)+S_{t}\left(\lambda B, \Delta p^{*}\right),
$$

where the second term is a present-value effect of forecasts of future changes in the target path,

$$
S_{t}(.)=(1-\lambda) \sum_{i=0}^{\infty}(\lambda B)^{i} E_{t}\left\{\Delta p_{t+i}^{*}\right\} .
$$

Following Tinsley (1993), we use a two-step estimation procedure where forecasts of the target path, $p^{*}$, are provided by a VAR model in the arguments of $\vec{x}_{t}$. Also, the quarterly discount factor is set to $B=0.98$, consistent with the annual postwar real return to equity of about 8 percent. Given estimates of the discount factor $B$ and of the VAR forecast model of $p^{*}$, the only remaining unknown parameter in the decision rule $(3)$ is the coefficient of the error-correction term, $(1-\lambda)$.

Estimates of the dynamic decision rule for the US manufacturing price using the sample span 1957Q1-1991Q4 are listed in table 1. 
Table 1: Estimated pricing rules for U.S. manufacturing.

\begin{tabular}{|c|c|c|c|c|c|c|}
\hline $\operatorname{Eqn}^{a}$ & $p_{t-1}-p_{t-1}^{*}$ & $\Delta p_{t-1}$ & $\left(p_{t-1}-p_{t-1}^{*}\right)^{+}$ & $R^{2}$ & $B G(12)$ & Mean $\operatorname{lag}^{b}$ \\
\hline 1 & $\begin{array}{c}-0.10 \\
(2.6)\end{array}$ & & & 0.40 & 0.00 & $M L=10$ \\
\hline 2 & $\begin{array}{c}-0.08 \\
(3.4)\end{array}$ & $\begin{array}{c}0.69 \\
(15.2)\end{array}$ & & 0.72 & 0.20 & $M L=2.9$ \\
\hline 3 & $\begin{array}{c}-0.11 \\
(2.5)\end{array}$ & $\begin{array}{c}0.65 \\
(13.3)\end{array}$ & $\begin{array}{c}-0.04 \\
(0.7)\end{array}$ & 0.73 & 0.17 & $\begin{aligned} M L^{-} & =2.2 \\
M L^{+} & =7.8\end{aligned}$ \\
\hline
\end{tabular}

The first line of table 1 presents statistics of the error-correction decision rule that follows from the simple two-root Euler equation. Considering it has only one free parameter, $1-\lambda$, the $R^{2}$ of this equation is respectable but the zero $p$-value of the Breusch-Godfrey statistic, $B G(12)$, indicates strong residual autocorrelations. Also, the estimate of a ten-quarter mean lag, $M L$, of price responses to unanticipated shocks is implausibly long.

The second equation reported in table 1 uses an extension developed in Tinsley (1993) where adjustment costs are generalized to include quadratic smoothing penalties not only of changes in the current price but of changes in moving averages of the price, such as might be associated with the survey findings noted earlier that some firms adjust every quarter but many adjust less frequently. One result of this change in the specification of dynamic costs is that lags in the dependent variable are added to the decision rule in (3). With this addition ${ }^{4}$, as shown for the second equation, the $R^{2}$ is much higher, the $p$-value of the BG statistic does not indicate residual autocorrelation at standard significance levels, and the mean lag is now 2.9 quarters, or around nine months.

\footnotetext{
${ }^{4}$ Alterations of the estimated decision rule are a bit more complicated: In the case of the second and third equations in table 1, the underlying Euler equation is fourth-order and two characteristic roots are used to discount future changes of the target price in $S_{t}($.$) . Another important empirical difference is that rational expectations restrictions imposed$ by the VAR forecast model of $p^{*}$ are rejected by the first decision rule in table 1 , but not by the remaining decision rules in the table. See additional discussion in Tinsley (1993).
} 
Finally, the third equation in table 1 exhibits another notable characteristic of postwar producer prices. The term in the third column replaces the error-correction term (listed in the first column) when the lagged price is above the lagged target price, $p_{t-1}-p_{t-1}^{*}>0$. As indicated, error-correction towards the target path is much smaller (and statistically insignificant from zero) when the price is above the target. The result is a strong positive asymmetry in dynamic adjustment of manufacturing prices, where positive corrections are faster than negative corrections. The mean adjustment lag in raising prices to catch up to higher target prices, $M L^{-}$, is about 2 quarters but the mean lag in reducing prices to approach lower target prices, $M L^{+}$, is nearly two years.

A finding of positive asymmetry in price adjustments helps reconcile two of the stylized facts regarding prices noted earlier. In inflationary periods, producers are not reluctant to raise nominal prices to cover rising nominal costs, as predicted by classical analyses. On the other hand, resistance to downward adjustments of nominal prices is consistent with the Keynesian notion that prices may get stuck temporarily at levels that are too high for market clearing, such as when output contractions are a preferred response to cyclical reductions in demand.

Even in the case of symmetric price responses, the adjustment cost rationale of gradual price adjustment seems to imply that the costs of price frictions exceed the costs of adjusting rates of production. The aim in the remainder of this paper is to illustrate an alternative conjecture that the gradual adjustments of producer prices may be due to transmission lags in information required for formulation of equilibrium prices. We suggest also reasons why system adjustments may be slower for price reductions than for price increases.

\section{Price Adjustment as Message Passing in Distributed Production.}

One drawback of macroeconomic analysis of pricing is that it ignores essential differences in pricing within the stages of production. It was widely recognized in early empirical studies, such as Mitchell (1913) and Means (1935), that prices tend to be less flexible as they advance from basic commodity inputs to specialized final demand outputs. This section presents a pricing model where the only dynamics are due to lags in the transmission of industry-specific information in a large-scale input-output system.

\subsection{Historical views of pricing in distributed production.}

In his extensive study of five U.S. business cycles from 1890-1910, Mitchell (1913, p. 102) noted that "the prices of raw materials respond more promptly and in larger measure to changes in business conditions than do the prices of their products. Since the ... partly manufactured products pursue a course intermediate between their raw materials and finished goods, it seems that the more manufacturing costs have been bestowed upon materials the steadier do their prices become."

Table 2, drawn from Mitchell (1913, p. 101), contrasts average reductions during business 
contractions in prices of raw materials, intermediate materials, and final goods.

Table 2: Price declines in 1893-4 and 1907-8 contractions.

\begin{tabular}{lccc}
\hline \hline & $\begin{array}{c}\text { Raw } \\
\text { materials }\end{array}$ & $\begin{array}{c}\text { Intermediate } \\
\text { materials }\end{array}$ & $\begin{array}{c}\text { Finished } \\
\text { goods }\end{array}$ \\
\hline Price fall $(\%)$ & -12 & -9 & -5 \\
\hline \hline
\end{tabular}

More than twenty years later, essentially the same phenomenon was observed by Gardiner Means (1935), who further illustrated that the extent of associated output contractions is inversely associated with the degree of price responsiveness. Extracts from a table in Means (1935, p. 405) are shown in table 3 .

Table 3: Drop in prices and production, 1929-1933.

\begin{tabular}{lccccc}
\hline \hline & $\begin{array}{c}\text { Agricultural } \\
\text { commodities }\end{array}$ & Oil & $\begin{array}{c}\text { Textile } \\
\text { products }\end{array}$ & $\begin{array}{c}\text { Iron \& } \\
\text { steel }\end{array}$ & $\begin{array}{c}\text { Agricultural } \\
\text { machinery }\end{array}$ \\
\hline Price fall (\%) & -63 & -56 & -45 & -20 & -6 \\
Output fall (\%) & -6 & -20 & -30 & -83 & -80 \\
\hline \hline
\end{tabular}

Among subsequent analyses of the increasing "downstream" inflexibility of manufacturing prices, many interpretations reduce to one of two explanations advanced by Mitchell and Means.

First, as noted in the quotation above, Mitchell suggested that rigid costs in the successive value-added stages of manufacturing, especially of labor, may account for much of the reduced price responsiveness. Wage rigidity, especially downward inflexibility, is also discussed by Pigou (1927), Keynes (1936), and such postwar interpretations as Tobin (1972). To gloss over a large empirical literature, the stylized fact appears to be that real wages appear to be slightly procyclical and price margins over unit costs are countercyclical. In other words, available evidence suggests that manufacturing prices are somewhat less cyclically responsive than unit costs of production or wages.

Second, in addition to the unsurprising implication that downward sloping demand schedules imply that reductions in demand may be partially offset by price reductions, Means (1935) indicted 
the noncompetitive structure of many manufacturing industries. An extensive literature has explored the relationship of producer price margins to various measures of industry market power, such as the Herfindahl concentration index. In contrast to Means' thesis, models of strategic pricing by oligopolies, such as Green and Porter (1984) and Rotemberg and Saloner (1986), suggest that high concentration may lead to episodes of sharply moving prices as individual oligopolists are induced, at various stages of the business cycle, to defect from implicit collusive agreements to maintain a common price.

Although many empirical studies indicate that price margins are higher in highly concentrated markets, evidence is inconclusive on the responsiveness of producer prices to changes in demand, Domowitz, Hubbard, and Peterson (1987). Interesting exceptions are Qualls (1979) and Eckard (1982), who suggest concentrated industries may respond faster due to better market information and inter-firm communications - an interpretation consistent with the costly communications model explored in this paper.

\subsection{A parallel Jacobi model of price adjustment.}

By contrast with standard adjustment cost interpretations of sticky producer pricing, the conjecture explored here is that the demand and cost information relevant to each producer is not instantaneously accessible and is transmitted through specific directed links between transacting agents. In the case of the downstream flow of input materials costs, it is not implausible that producers in each stage of production respond to received ripples in input prices with at least a one-cycle lag.

The industry-to-industry transmission of current cost information is described by Gordon (1990, p. 1150-1), "the typical firm has no idea of the identity of its full set of suppliers when all the indirect links within the input-output table are considered. Because the informational problem of trying to anticipate the effect of a currently perceived nominal demand change on the weighted-average cost of all these suppliers is difficult to formulate and probably impossible to solve, ... the sensible firm waits by the mailbox for news of cost increases and then ... passes them on as price increases."

A simple description of this "waiting by the mailbox" transmission of cost increases is a one-cycle lagged version of the open-Leontief pricing system adapted for Cobb-Douglas production

$$
p_{t}=A^{\prime} p_{t-1}+v_{t}
$$

where $p_{t}$ denotes the $n \times 1$ vector of $\log$ prices of outputs produced in $n$ industries; $A$ is the $n \times n$

\footnotetext{
${ }^{5}$ Differences between the price lag responses of individual producers and of aggregate price indexes are discussed in Gordon (1981, 1990) and Blanchard (1987).
} 
Leontief input-output matrix, and $v_{t}$ is an $n \times 1$ forcing vector. Consistent with the basic model in section 2 , each industry forcing term $v_{i}$ is the sum of the $\log$ of the industry markup $m_{i}$ and the $\log$ of unit labor costs, $w_{i}-\rho_{i}$, where $w_{i}$ is the industry log wage rate and $\rho_{i}$ is log labor productivity. The $i$ th column of $A$ contains the cost shares of purchased material inputs; using earlier notation, $A_{., i}^{\prime}=\left[\theta_{1, i}, \ldots, \theta_{n, i}\right]^{6}$

Of course, the dynamics of this simple staggered pricing system are equivalent to parallel Jacobi solutions of a linear system. Given a fixed unit cost impulse $v^{*}$, the desired price response is

$$
\begin{aligned}
p^{*} & =\left[I-A^{\prime}\right]^{-} v^{*} \\
& =\left[I+A^{\prime}+A^{\prime 2}+A^{\prime 3}+\ldots\right] v^{*} \\
& =p_{1}+\left(p_{2}-p_{1}\right)+\left(p_{3}-p_{1}\right)+\ldots
\end{aligned}
$$

The iteration expansion on the third line has two implications for successive price adjustments. First, the "error-correction" adjustment rates of this system are determined by the characteristic roots of $A$. That is, the reduction of distances between the current price and the target price vectors is 7

$$
p_{t}-p^{*}=A^{\prime}\left(p_{t-1}-p^{*}\right) .
$$

Second, each stage of successive price revisions adjusts for the change in costs of preceding stages of production. That is, $p_{1}$ adjusts for the initial change in unit value-added costs in each industry. After these costs are passed on to the next downstream stage of processing, $p_{2}-p_{1}$ denotes the adjustment in each industry to the consequent change in costs of direct suppliers that is, the possible $n$ suppliers of inputs to each industry represented by the columns of $A$. The next round of revisions, $p_{3}-p_{2}$, incorporates responses to changes in the costs of the suppliers of the direct suppliers, i.e. the $n^{2}$ suppliers once-removed. The next revision, $p_{4}-p_{3}$, accounts for price adjustments due to changes in the costs of the possible $n^{3}$ suppliers twice-removed, and so on.

\footnotetext{
${ }^{6}$ Because the pricing system is open, the sum of nonzero elements in each column of A is nonnegative and less than unity; consequently, $\left[I-A^{\prime}\right]$ is strictly diagonally dominant, invertible, and its spectral radius is less than one, vid. Horn and Johnson (1985).

${ }^{7}$ Here, we focus on alternative interpretations of the error-correction adjustment term in the optimal decision rule (3) of the "representative" manufacturing system. The additional forward-looking term in equation (3) is only required if there are perceived adjustment lags. Although we suspect that the effect of this second term is not difficult to replicate after the form of system lags is established, perhaps through multi-period pricing contracts in vertical agreements, this refinement is not explored in this paper.
} 


\subsection{An empirical input-output example.}

To provide concrete illustrations of the timing of information flows under different communication structures among industries, a 356-industry input-output system is constructed from the US Department of Commerce (1991) industry use and make tables for 1982.

Also, to obtain data-based estimates of discrepancies between actual prices $p$ and target prices $p^{*}$, monthly target prices for industries are estimated using a procedure similar to that outlined earlier. ${ }^{8}$

Cointegration regressions are used to construct estimates of the trend or target level of value-added costs in the $i$ th industry, $v_{i, t}^{*}$,

$$
\begin{aligned}
p_{i, t}-\sum_{j} a_{j, i} p_{j, t} & =b_{0, j}+b_{1, i} w_{i, t}+b_{2, i} t+e_{i, t} \\
& =v_{i, t}^{*}-\tilde{v}_{i, t}^{*}
\end{aligned}
$$

where the second line indicates that the residual, $e_{i, t}$, is an estimate of the discrepancy between the target unit cost of value-added and the construction implied by current prices. Denoting $\tilde{v}_{t}^{*}$ as the $n \times 1$ vector of deviations in value-added price for the 356 industries, estimates of the target deviations in industry producer prices is provided by

$$
\tilde{p}_{t}^{*}=\left[I-A^{\prime}\right]^{-} \tilde{v}_{t}^{*}
$$

A convenient estimate of the average size of the log gaps in value-added and final prices is provided by the sample means of the absolute values, $\left|\tilde{v}^{*}\right|$ and $\left|\tilde{p}^{*}\right|$. Averaged over all 356 industries, the mean absolute values of the value-added and producer price gaps are 0.022 and 0.025 , respectively.

Hereafter, because we will often discuss responses to price changes, unless otherwise indicated, it will be notationally convenient to drop the absolute value " ||" and gap " $\tilde{v}$ " notation and simply use $p$ and $v$ to denote $\left|\tilde{p}^{*}\right|$ and $\left|\tilde{v}^{*}\right|$.

Under this notational convention, the industry mean lag responses by parallel Jacobi $(P J)$ iterations to an initial cost discrepancy, $v$, are

$$
\begin{aligned}
M L(P J) & =\left[I+2 A^{\prime}+3 A^{\prime 2}+4 A^{\prime 3}+\ldots\right] v /\left[I-A^{\prime}\right]^{-} v \\
& =\left[I-A^{\prime}\right]^{-}\left[I-A^{\prime}\right]^{-} v /\left[I-A^{\prime}\right]^{-} v
\end{aligned}
$$

\footnotetext{
${ }^{8}$ Although some prices were available for the full postwar period, a common sample of the 356 industry producer prices was available only for the 1986.01 - 1994.02 span. Consequently, "cointegration" regressions discussed below are only suggestive of what might be obtained for a longer sample.
} 
where " $/$ " denotes element-by-element division of the numerator and denominator vectors. Using the empirical estimates of $v$, the average industry mean lag is 1.93 iteration cycles.

The first two lines in table 4 compare empirical estimates of industry price mean lags (in months) and parallel Jacobi mean lags (in iteration cycles) for approximately the same industry groupings used by Means (1935).

Table 4: Characteristics of representative production stages.

\begin{tabular}{lccccc}
\hline \hline & $\begin{array}{c}\text { Agricultural } \\
\text { commodities }\end{array}$ & Oil & $\begin{array}{c}\text { Textile } \\
\text { products }\end{array}$ & $\begin{array}{c}\text { Iron \& steel } \\
\text { forgings }\end{array}$ & Machinery \\
\hline$M L^{a}$ & 5.3 & 6.2 & 6.9 & 7.9 & 11.3 \\
$M L(P J)^{b}$ & 1.4 & 1.0 & 2.0 & 2.0 & 1.9 \\
$\begin{array}{l}\text { Materials input } \\
\text { share (\%) }\end{array}$ & 38 & 6 & 58 & 41 & 37 \\
$\begin{array}{l}\text { Average number } \\
\text { of suppliers }\end{array}$ & 48 & 34 & 52 & 68 & 93 \\
\hline \hline
\end{tabular}

${ }^{a}$ Mean lag in months.

${ }^{b}$ Mean lag in iteration cycles.

${ }^{c}$ Based on industry direct suppliers with input shares greater than 0.0001 .

Although the correspondence is not exact, both mean lag estimates suggest a tendency for slower adjustment speeds of prices in succeeding stages of production. The third line suggests that this is not merely due to the amount of purchased materials used in production. Except for extractive industries, the average share of output due to purchased materials from other industries in this input-output system is about $40 \%$. As shown in the fourth line of the table, a more appropriate indicator of mean lags in price adjustment appears to be the complexity of production and coordination of inter-firm communications, as measured here by the average number of industry direct suppliers.

Of course, there is no obvious way to translate iteration cycles into calendar time. Nevertheless, if we assume surveys are correct in suggesting that the average firm adjusts its price about once a year, then a mean lag estimate of 1.9 cycles would translate to a calendar mean lag of about 23 months, considerably longer than the average mean lag of about 9 months indicated earlier for historical manufacturing prices. 
Obviously, there can be many overstatements of inter-industry information lags in the stylized parallel Jacobi example. For example, firms may be aware of key pressures on the prices of inputs purchased from their direct suppliers. To obtain a crude decomposition of the cycles of information embedded in the mean lag estimate, note that an approximate linear decomposition is

$$
\begin{aligned}
M L(P J) & =\left[I+2 A^{\prime}+3 A^{\prime 2}+4 A^{\prime 3}+\ldots\right]\left[I-A^{\prime}\right]^{-} v /\left[I-A^{\prime}\right]^{-} v \\
& \simeq\left[I+2 A^{\prime}+3 A^{\prime 2}+4 A^{\prime 3}+\ldots\right][p / p] \\
& \equiv \overrightarrow{1}+2 M L(2)+3 M L(3)+\ldots
\end{aligned}
$$

where $\overrightarrow{1}$ is a $356 \times 1$ unit vector.

We would not expect the simple model of parallel Jacobi iterations to provide good predictions of cross-industry variations in mean lag adjustments. Thus, it is not surprising that the correlation between industry estimates of historical mean lags, $M L$, and the corresponding parallel Jacobi mean lag measures, $M L(P J)$, is only .10. A more revealing insight into the timing of inter-industry flows is obtained by regressing the 356 industry estimates of historical mean lags, $M L$, on the parallel Jacobi mean lags, $M L(P J)$, and initial terms of the approximate expansion in equation (7).

Table 5: Regression of industry mean lags, ML, on iteration mean lags, $M L(P J)$, and iteration stages.

\begin{tabular}{ccccc}
\hline \hline$M L(P J)$ & $M L(2)$ & $M L(3)$ & $M L(4)$ & $R^{2}$ \\
\hline 16.8 & -32.7 & & & 0.12 \\
$(6.7)$ & $(6.4)$ & & & \\
29.0 & -24.7 & -55.4 & & 0.20 \\
$(9.4)$ & $(4.9)$ & $(6.1)$ & & \\
27.5 & -21.1 & -66.2 & 24.1 & 0.20 \\
$(8.1)$ & $(3.6)$ & $(5.1)$ & $(1.1)$ & \\
\hline \hline
\end{tabular}

Using the parallel Jacobi mean lag estimates, $M L(P J)$, as a benchmark, the negative contributions of initial iteration responses suggest that historical mean lags are somewhat faster in response to the average information contained in the initial rounds of information transmission in the chain of production. However, this faster information transmission does not seem to penetrate much 
deeper than early receipt of information on the input costs of direct suppliers, as summarized in the $M L(3)$ terms.

Thus, it appears that a more realistic model of empirical price adjustment lags should allow for industry differences in speeds of processing information relative to the fixed lags depicted in the simple parallel Jacobi solution. The remainder of this section discusses three modifications of the parallel Jacobi solution that may be sources of different speeds of price adjustments by individual industries.

\subsection{Acceleration through communication groups.}

The input-output system highlights only the structure of disaggregated production of heterogeneous commodities and does not address the varying degrees of inter-industry information that may be available through alternative organization of corporate control. For example, in contrast to the parallel Jacobi model of isolated industries at each stage of production, all relevant production stages might be controlled by the management of a single vertical monopoly. In this case, it would seem unlikely that relevant information on altered costs in any phase of production would not be rapidly disseminated to all plants controlled by the vertical organization.

As reviewed by Perry (1989), there are also many forms of vertical "quasi-integration" ranging from production contracts, leasing agreements, and marketing franchises to equity investments, all of which are aimed at obtaining some of the information and control benefits of vertical integration. Even at the level of least intrusion on corporate control, trade organizations provide a forum for collecting and sharing information on recent trends in demand and costs of purchased materials.

We assume that information on current shocks in various horizontal and vertical stages of production is effectively processed within the relevant group of industries before submitting revised prices to the general round of inter-industry price communications defined by the global parallel Jacobi iteration. That is, industries organized into communication groups use all available intra-group information prior to submitting revised prices.

From the perspective of the $m$ industries in a given communication group, the global production system is divided into member and non-member groupings:

$$
\begin{aligned}
& p_{1, t}=A_{11} p_{1, t}+A_{12} p_{2, t-1}+v_{1} \\
& p_{2, t}=A_{21} p_{1, t-1}+A_{22} p_{2, t-1}+v_{2}
\end{aligned}
$$

where $A_{i, j}$ denotes partitions of the $n \times n$ input-output matrix, $A^{\prime} ; p_{1}$ is $m \times 1$; and $p_{2}$ is $(n-m) \times 1$. The first equation describes the response by the $m$ member industries in the $p_{1}$ communication group to current information within the group. The second equation is a conjecture regarding adjustment of the $n-m$ prices in $p_{2}$ of the non-member industries. For the moment, we assume this 
equation is inaccessible to members of the $p_{1}$ communication group because the elements of $A_{21}$, $A_{22}$, and $v_{2}$ are not known to these industries. Under this information structure, communications within the $m$-industry group lead to a $p_{1}$ adjustment in the current iteration of

$$
p_{1, t}=\left[I-A_{11}\right]^{-}\left[A_{12} p_{2, t-1}+v_{1}\right]
$$

which makes more effective use of available information in $p_{2, t-1}$ and $v_{1}$ than does the parallel Jacobi solution, so the mean lags of price adjustments in the $p_{1}$ group will be reduced.

Of course, contrary to the uninformed view of the $m$ member industries of the $p_{1}$ group, there may be one or more information groups among the $n-m$ non-member industries controlling $p_{2}$. Indeed, if all groups are separable $\left(A_{12}=A_{21}=0\right)$, then full price adjustments to the news in $v_{1}$ and $v_{2}$ could be completed in a single block-Jacobi iteration, with an associated mean lag of one iteration. Note also that intra-group communications can lead to system acceleration spillovers because responses to information within the $p_{1}$ group that might have taken several iterations to reach non-member industries will now be disclosed by transmitting the accelerated price adjustments in the current system iteration cycle, $p_{1, t}$.

The solution in equation (8) also suggests a rough estimate of the cost of communications among the $m$ industries within the $p_{1}$ communication group. Inversion of the $m \times m$ matrix $I-A_{11}$ can be approximated by the familiar expansion $I+A_{11}+A_{11}^{2}+A_{11}^{3}+\ldots$. Each matrix multiplication requires $m^{2}$ message transmissions, and $O(\log m)$ terms are required in the expansion approximation of the inversion. ${ }^{9}$ Assuming the costs of intra-group communications are shared equally, each industry's share of intra-group communication costs is approximately $m O(\log m)$.

\subsection{Additional acceleration by feedback conjectures.}

Given convex communication cost pressures to contain the size of the communication group, it is likely that some group members are aware of important suppliers who are not members. In turn, other group industries may be suppliers of these excluded suppliers. By pooling this information, group members can approximate the roundtrip effects of current changes in the $p_{1}$ prices on the prices of external industries who are expected to subsequently alter input prices to members of the $p_{1}$ group.

However, to remain consistent with our original assertion that industries have very limited knowledge outside explicit communication groups, we assume the industries who control $p_{1}$ have only an aggregated view of industries in the external $p_{2}$ group. Under this restriction, the

\footnotetext{
${ }^{9}$ See JáJá (1992), p. 409, where $O(r)$ denotes that there exist positive constants $k$ and $r^{\prime}$, such that for all $r>r^{\prime}$ the number of expansion terms is bounded by $k r$.
} 
conjectured feedback response to a current iteration change in $p_{1}$ prices is

$$
A_{12} g^{-} g\left[I-A_{22}\right]^{-} A_{21}\left(p_{1, t}-p_{1, t-1}\right),
$$

where $g$ is a $k \times(n-m)$ aggregation matrix with $k \ll(n-m) \cdot{ }^{10}$ A later section will illustrate the case where the external non-member group is aggregated to a single industry, reducing $g$ to a $1 \times(n-m)$ aggregation vector.

\subsection{Retardation of industry adjustments through non-transmissions.}

Although the focus of this paper is primarily on organization of inter-industry communications that can accelerate simple parallel Jacobi transmissions, we should note there is a long list of conditions that may slow the adjustment of producer prices.

Stale quotes may be a problem in large communication groups if the transmission chain of required messaging within the group is lengthy. Although we largely neglect the role of horizontal firms within an industry, there may be strategic reasons for firms to slow communications of key information or to transmit misinformation.

If price transmissions are costly, it seems likely that firms may decide to internalize small discrepancies from target prices and transmit only sizable changes in prices. Under this interpretation, "menu costs" of posting price changes may be a source of stale quotations. ${ }^{11}$

There are likely to be asymmetric differences in responses to downstream flows of cost changes and reverse flows of information on changes in final demand. Downstream flows of actual cost changes are visible commitments by suppliers to changes in input prices. Receiving firms have an incentive to pass on higher costs of intermediate materials because to not do so risks lower profits or even bankruptcy.

Reverse transmissions of responses to changes in final demand are more problematic and depend on the competitive structure of the stream of producing industries. Remember that the effective value-added component, $v$, at each production stage contains both the marginal cost of the value-added in that industry, $c$, and the industry markup, $m$, which is a decreasing function of the perceived price elasticity of demand, $\eta$. Although changes in demand can alter both marginal cost and demand elasticities, often the former is relatively flat and invariant to moderate changes

\footnotetext{
${ }^{10} \mathrm{By}$ contrast, if all elements in $A^{\prime}$ partitions associated with the $p_{2}$ group were known to industries in the $p_{1}$ group, any "aggregation" conjecture should fully preserve this information, $g^{-} g=I_{n-m}$. Use of conjectural aggregation within communication blocks and global Jacobi iterations of the full system is similar to the recursive aggregate/disaggregate algorithms discussed in Vakhutinsky, Dudkin, and Ryvkin (1979) and Tsai, Huang, and Lu (1994).

${ }^{11}$ As explored by Tsiddon (1993) and Ball and Mankiw (1992), the combination of menu costs and positive trends in target prices can induce positive pricing asymmetries.
} 
in the level of output. The elasticity of demand may be a more likely source of countercyclical movements that induce pro-cyclical adjustments of target prices.

In the case of a nominal demand shift, an industry's share of final demand could be maintained if all prices in the chain of production move proportionately. In inflationary periods, independent industries at each stage of production may increase prices with alacrity since the consequence of moving before suppliers is temporary profits due to higher margins over costs. However, in the case of price reductions, a failure to coordinate significant price reductions with suppliers can be severe illiquidity or bankruptcy. Thus, downstream firms may be "stuck" for some time with lower sales until lower cost agreements are struck with upstream suppliers.

It is especially likely that independent upstream suppliers, who are not bound by vertical agreements, may be relatively insensitive to movements in final demand elasticity. The elasticity of derived demand for the industry producing, say, the $i$ th materials input is $\eta_{i}=\theta_{i} \eta+\left(1-\theta_{i}\right) \sigma$, where $\theta_{i}$ is the cost share of the $i$ th input, $\eta$ is the price elasticity of final demand, and $\sigma$ is the factor elasticity of substitution in production ( $\sigma=1$ in Cobb-Douglas production), Waterson (1982). Substitution in production is prominent in this expression because a consequence of a stand-alone input price increase is to shift the composition of final demand towards less expensive inputs. Thus, if the contribution of the supplying industry to final product, $\theta_{i}$, is small then the derived demand elasticity of the upstream producer is likely to be insensitive to moderate variations in the elasticity of final demand, $\eta$.

Thus, apart from explicit coordination arrangements such as vertical mergers, it seems likely that backward or upstream effects of shifts in final demand are likely to be smaller and have slower transmission rates than forward or downstream flows of rising costs. Also, it appears that less inter-industry coordination is required to pass along incurred cost increases than desired price reductions.

\section{Searching for Block Patterns in a Large-Scale System}

Consider the pricing system described in equation (4),

$$
p_{t}=A^{\prime} p_{t-1}+v_{t}
$$

where $A$ is the input-output $(\mathrm{I} / \mathrm{O})$ matrix, $v$ is a forcing vector, and $p$ is the industry price vector. We consider the effects of industries coalescing into groups in order to share information; each industry belongs to exactly one group. A group, or block, of industries is represented by a subset of the rows of $A^{\prime}$. The industries in a group solve their I/O subsystem to get new prices at time $t$, using current price information from other industries within the group, and lagged $t-1$ price information from industries outside the group. Each communication group is solved simultaneously, and then 
the process is repeated until the entire price array converges.

This solution process can be thought of as modeling the exchange of cost and demand information among firms and their customers and suppliers. The goal of firms is to be able to adjust to the optimal price, $p^{*}$, as fast as possible. We measure the speed of convergence by the mean iteration lag, defined in the first line of equation (7), to estimate how quickly prices converge to the optimal price in response to external shocks.

The 356-industry example that we consider is highly abstracted from the dimensions of a problem faced by an actual firm. A firm in the auto industry, for example, may have a chain of production involving thousands of suppliers. However, even in our 356-industry example, the computational problem of finding optimal communication groups is a daunting one, from the perspective of either an individual firm or a central planner. The scope of the possible search space is enormous; the number of different groups that an individual industry might join is $2^{355}$, an unimaginably large number. The related feedback vertex set problem was shown to be NP-complete by Karp (1972); see also Garey and Johnson (1979). ${ }^{12}$

Note that the fastest convergence will occur when each industry has the recent price information on every other industry - i.e., when the entire $356 \times 356$ matrix is solved as a single block. In real life, however, there is a cost associated with gathering current information that mitigates against this sort of arrangement. Consequently, we define a cost function that charges industries for the information they gain through communication with members of their own group. The cost is related to the computational complexity of solving the subsystem defined by the group. The cost per group member increases with the size of the group; thus, very large groups are not attractive since the cost of communication exceeds the benefits to be gained.

\subsection{Estimating the cost of communication.}

We derive an estimate of communication cost that is calibrated in system iteration or "cycle" units as follows. In a standard parallel Jacobian iteration, the column vector of industry mean lags is computed as

$$
m l=\frac{\left(I+2 A^{\prime}+3\left(A^{\prime}\right)^{2}+4\left(A^{\prime}\right)^{3}+5\left(A^{\prime}\right)^{4}+\ldots\right) v}{\left(I-A^{\prime}\right)^{-} v} .
$$

Note that the first time this criterion addresses the cost of contacting unknown suppliers (i.e., industries that are upstream in the flow of production, but are not direct suppliers) is in the third term,

$$
\frac{3\left(A^{\prime}\right)^{2} v}{\left(I-A^{\prime}\right)^{-} v}
$$

\footnotetext{
${ }^{12} \mathrm{~A}$ problem that is NP-complete has been proved to be equivalent in difficulty to a large number of other problems widely regarded by computer scientists to have no polynomial-time solution algorithm, and thus to be intractable for large problem instances.
} 
which is proportional to the relative price adjustment due to changes in the costs of the suppliers of direct suppliers. Suppose each industry has $k$ suppliers; then each industry must contact (in the worst case) $k^{2}$ suppliers in order to learn about these costs one period before they filter through the costs of the direct suppliers.

We assume that industries want to minimize mean lag responses. By contacting all $k^{2}$ of their suppliers' suppliers, they could reduce their mean lag to

$$
m l a=\frac{\left(I+2\left(A^{\prime}+\left(A^{\prime}\right)^{2}\right)+4\left(A^{\prime}\right)^{3}+5\left(A^{\prime}\right)^{4}+\ldots\right) v}{\left(I-A^{\prime}\right)^{-} v} .
$$

This results in a reduction in the mean lag of

$$
m l-m l a=\frac{\left(A^{\prime}\right)^{2} v}{\left(I-A^{\prime}\right)^{-} v} .
$$

In the case of parallel Jacobian responses, the average value of $m l$ is 1.9294 cycles and the average of $(m l-m l a)$ is 0.1675 cycles. The average number of suppliers per industry is around 25; thus an estimate of the mean lag reduction per supplier contact is $c=$ mean $(m l-m l a) /(25 \times 25)=$ 0.000268. Under the assumption of parallel Jacobi responses, this is a lower bound estimate of the cost of a contact with an individual supplier, in the sense that the perceived cost of contact must have exceeded the reduction in the mean lag that could have been obtained by contacting the additional suppliers.

As described in section 3, each industry's share of the number of communications required to solve an $m$-industry group is about $m^{2} \log m$. The logarithmic factor is an estimate of the number of terms required in the expansion of the inversion; our experience with matrices of this size suggests that $3 \log m$ is a more appropriate approximation. Consequently, our estimate of the communication costs associated with a group of $m$ industries is $3 \mathrm{~cm}^{2} \log m$ (where $c=0.000268$ as derived above); the per-industry share of this cost is thus $3 \mathrm{~cm} \log m$. This cost is added to the average mean lag to determine the total performance measure of a partition of industries into groups. Obviously, the smaller the resulting number, the better.

\subsection{Computing environment.}

The computations described in this paper were run on Sun workstations in a Unix environment. The application programs were written in $\mathrm{C}++$, using the SPARCOMPILER $\mathrm{C}++3.0$ compiler from SunPro. Extensive use was made of the MatClass C++ matrix libraries, written by Birchenhall (1993). While these libraries were reliable and simplified the programming a great deal, their performance was at times somewhat slow. Consequently, portions of the code that were to be executed many times were written as iterated scalar operations, rather than as matrix operations 
using MatClass library functions. The code was written in a style that combines elements of the object-oriented and procedural paradigms. Industries, groups of industries, and collections of groups were each encapsulated as $\mathrm{C}++$ classes.

Note that the "parallel" Jacobian iterations were actually performed sequentially, though independently so as to simulate parallel computation. Since we were not measuring performance by elapsed time and running times were (usually) not excessive, there was little need to actually run them in parallel. Exceptions to the latter were the genetic algorithms, discussed later, which were particularly computation-intensive. Future work may implement a parallel version of this code, using the PVM libraries written by Geist et al. (1993).

\subsection{Forming groups by rules-of-thumb.}

We first consider several simple algorithms for forming groups. Each is a rule-of-thumb for clustering into communication groups which requires only local information on the part of individual industries. These include such basic ideas as industries joining groups that contain their largest suppliers or customers, as well as forming random groups; the latter is included primarily as a baseline. The algorithms we have studied are as follows:

k-Largest-suppliers Each industry's group merges with the groups containing its $k$ largest suppliers.

k-Largest-customers Each industry's group merges with the groups containing its $k$ largest customers.

Suppliers-over-f Each industry's group merges with all groups that contain an industry that supplies at least the fraction $f$ of its inputs.

Customers-over-f Each industry's group merges with all groups that contain an industry that purchases at least the fraction $f$ of its outputs.

Random-p Groups are formed randomly. In particular, with probability $p$ each industry forms a new group. With probability $1-p$ it joins an existing group, with the particular group selected equiprobably from all existing groups.

The table below shows some statistics on the collections of groups generated by these algorithms, as well as the performance of the collections as measured by their mean lags and communication costs. 
Table 6: Performances of alternative communication groupings.

\begin{tabular}{|c|c|c|c|c|c|}
\hline $\begin{array}{l}\text { Algorithm } \\
\text { used for } \\
\text { forming groups }\end{array}$ & $\begin{array}{l}\text { Number } \\
\text { of } \\
\text { groups }\end{array}$ & $\begin{array}{l}\text { Largest } \\
\text { group } \\
\text { size }\end{array}$ & $\begin{array}{l}\text { Average } \\
\text { mean lag } \\
(\mathrm{AML})\end{array}$ & $\begin{array}{c}\text { Average } \\
\text { communication } \\
\text { cost }(\mathrm{ACC})\end{array}$ & $\mathrm{AML}+\mathrm{ACC}$ \\
\hline Random- 0.2 & 78 & 168 & 1.6239 & 0.3307 & 1.9546 \\
\hline Random- 0.4 & 158 & 59 & 1.9050 & 0.0356 & 1.9407 \\
\hline Random-0.6 & 215 & 21 & 1.9151 & 0.0052 & 1.9203 \\
\hline 1-Largest-customer & 160 & 20 & 1.6739 & 0.0085 & 1.6824 \\
\hline 2-Largest-customers & 24 & 324 & 1.1171 & 1.3706 & 2.4876 \\
\hline 1-Largest-supplier & 52 & 74 & 1.4514 & 0.1069 & 1.5583 \\
\hline 2-Largest-suppliers & 1 & 356 & 1.0000 & 1.6816 & 2.6816 \\
\hline Customers-over- 0.075 & 155 & 174 & 1.3372 & 0.3534 & 1.6905 \\
\hline Customers-over- 0.10 & 207 & 21 & 1.5193 & 0.0392 & 1.5585 \\
\hline Customers-over-0.125 & 236 & 25 & 1.5775 & 0.0104 & 1.5879 \\
\hline Suppliers-over-0.075 & 135 & 194 & 1.2990 & 0.4484 & 1.7474 \\
\hline Suppliers-over-0.10 & 195 & 83 & 1.4830 & 0.0738 & 1.5568 \\
\hline Suppliers-over-0.125 & 224 & 29 & 1.5529 & 0.0159 & 1.5688 \\
\hline
\end{tabular}

Using the mean lag adjusted for the costs of inter-industry communication, randomly-formed groups of industries result in a performance measure of about 1.92-1.96 cycles, with performance varying little according to the size and number of groups. This is similar to the value of 1.93 cycles obtained when each industry comprises its own group; i.e., when the entire matrix is solved by a single parallel Jacobian algorithm. ${ }^{13}$

Thus, there appears to be no benefit to forming groups at random. At the other end of the spectrum, all 356 industries are placed into a single group when the 2-Largest-suppliers algorithm is run. The average mean lag then takes on its best possible value, which is one iteration cycle. However, the cost of communication among such a large number of industries pushes the performance measure up to 2.68 cycles - the worst among all algorithms tested.

The best results are achieved by the 1-Largest-supplier, Suppliers-over-0.10, and Customers-over- 0.10 algorithms. When the thresholds for the latter two are increased to 0.125 ,

\footnotetext{
${ }^{13}$ We optimistically suggest that perhaps the fact that a variety of random group collections result in performances similar to each other, and to the case where all groups have size one, indicates that our performance measure is well-calibrated.
} 
they continue to perform well. Note that the number of groups generated by these algorithms varies widely. Although the performances of the 1-Largest-supplier and Customers-over-0.10 algorithms are nearly identical, the number of groups formed by the latter is 207 , while the number formed by the former is only 52. Along the same lines, compare the results for Random- 0.6 and Customers-over-0.10. The number of groups generated by these algorithms, as well as the size of the largest group, are quite similar. However, note the difference in the average mean lags 1.92 for the random algorithm versus 1.52 for the threshold algorithm. This sizable difference graphically illustrates the increased efficiency of a collection of groups formed by a reasonable rule-of-thumb, as compared to the performance of random groupings with a comparable degree of clustering.

Although the input-output matrix, $A$, is relatively sparse, the groupings in the table also indicate that all elements or industries are eventually connected through a transmission chain of common inputs or customers. Note that the 2-Largest-suppliers algorithm clusters all 356 industries into a single group. That is, there is no proper subset of industries such that for each industry in the subset, the subset contains its two largest suppliers. The 2-Largest-customers algorithm places 324 of the 356 industries into a single group, and extending this to the 3-Largest-customers algorithm results in one 356-industry group. We also note that connectivity is somewhat greater in the upstream direction, i.e. in the direction of suppliers. For example, the 1-Largest-supplier algorithm results in fewer groups — as well as a larger dominant group — than does the 1-Largest-customer algorithm. The same is true of the 2-Largest-suppliers algorithm when compared with 2-Largest-customers, and each of Suppliers-over-0.075/0.10/0.125 when compared with their customer-based counterparts. ${ }^{14}$

If we assume, as suggested earlier, that a representative interval between price adjustments is on the order of a year, then the difference between a value of about 1.9 (as might be obtained from either random groups or the absence of any groups at all) and a value of about 1.5 (as results from the best of the rules-of-thumb we tested) may correspond to a difference in average price adjustment frequency of around five months. Thus, the way in which firms in different industries share information may significantly affect the speed with which they update their prices in response to external shocks.

\footnotetext{
${ }^{14}$ This asymmetry may contribute to asymmetric price movements discussed earlier such as greater responsiveness to upstream input costs than to changes in downstream final demands.
} 


\section{Variations}

This section explores how the performances of communication groups may alter under different informational assumptions. First, we consider the effect of industries taking into account the effects of their own price adjustments, not just on other members of their group, but also on the aggregation of all industries outside their communication group. Next, we investigate what effect occasional communications failures — both within and between groups — have on the speed of price adjustments.

\subsection{An aggregated view of the rest of the world.}

In our basic model, industries exchange current price information with members of their own group until they have solved the corresponding subblock of the $\mathrm{I} / \mathrm{O}$ pricing system. During this communication period, they use the previous period's price information from all non-member industries outside the group. Thus, intra-group price iterations are performed only on rows of $A^{\prime}$ that correspond to members of the group. Members of a group do not attempt to solve rows of the $A^{\prime}$ matrix that correspond to industries in other groups, such as would be required to anticipate the effects of member price changes on non-member industries and, in turn, the effects of non-member induced price changes back on the production costs of members. This exclusion restriction seems reasonable because calculation of non-member feedback effects would require that member industries have detailed knowledge of the current cost structure of the complete US manufacturing sector.

However, we do not dismiss the possibility that member industries form approximate estimates of the effects of member price changes on non-member industries. To illustrate, we introduce a variation of the original model where industries use a simplified, aggregated view of the "rest of the world" (i.e., industries outside of their group) in setting prices.

Let $n$ be the total number of industries, and $m$ be the number of industries in a group $G$. Without loss of generality, we reorder the rows of $A^{\prime}$ such that the rows corresponding to the $m$ industries in group $G$ come first, and partition $A^{\prime}$ as follows: ${ }^{15}$

$$
A^{\prime}=\left[\begin{array}{ll}
A_{11} & A_{12} \\
A_{21} & A_{22}
\end{array}\right],
$$

where $A_{11}$ is $m \times m, A_{12}$ is $m \times(n-m), A_{21}$ is $(n-m) \times m$, and $A_{22}$ is $(n-m) \times(n-m)$.

\footnotetext{
${ }^{15}$ Note that the partitions indicated are those of $A^{\prime}$, the transpose of $A$.
} 
The I/O system can then be partitioned as

$$
\left[\begin{array}{l}
p_{1} \\
p_{2}
\end{array}\right]=\left[\begin{array}{ll}
A_{11} & A_{12} \\
A_{21} & A_{22}
\end{array}\right]\left[\begin{array}{l}
p_{1} \\
p_{2}
\end{array}\right]+\left[\begin{array}{l}
v_{1} \\
v_{2}
\end{array}\right],
$$

where $p_{1}$ and $v_{1}$ are $m \times 1$ and $p_{2}$ and $v_{2}$ are $(n-m) \times 1$. The input rows for $p_{1}$ contain within-group relations $\left(A_{11}\right)$ and input weights due to $p_{2}$ prices $\left(A_{12}\right)$. Both $A_{11}$ and $A_{12}$ are known to industries in $G$. However, we assume that industries in $G$ know only the sums of columns in $A_{21}$, where these totals are the ratios of input shipments from industries in $G$ to the production by non- $G\left(p_{2}\right)$ industries. By contrast, we assume industries in $G$ know nothing useful about $A_{22} ;{ }^{16}$ the particular default used here to represent this lack of information is that industries in the G group assume $A_{22}$ is zero.

Under these information assumptions, at each parallel Jacobian iteration, prices in group $G$ are solved by

$$
p_{1}(t)=A_{11} p_{1}(t)+A_{12} p_{2}(t-1)+v_{1}+B\left(p_{1}(t)-p_{1}(t-1)\right)
$$

where $p_{1}(t)$ is iterated to a solution but $p_{2}$ is held at its last known $(t-1)$ value. $B$ is the feedback adjustment which accelerates any change in $p_{1}$ from its last known value by "rationally" anticipating the eventual response of $p_{2}$ to the revision in $p_{1}$. The solution for $B$ obtained by substitution from equation 9 is

$$
B=A_{12}\left(I-A_{22}\right)^{-} A_{21}
$$

which is now approximated by member industries as

$$
A_{12} g^{-} g A_{21}
$$

where $g$ is the $1 \times(n-m)$ aggregation vector $\iota^{\prime} /(n-m) ; g^{-}=\iota$; and $\iota$ is the $(n-m) \times 1$ unit column vector. That is, $g$ is simply a row-averaging operator, and $g^{-}$is a column-summing operator. Thus, member industries approximate the $(n-m)$ non-member industries as a single external "industry".

Table 7 illustrates the effect of incorporating this restrictive aggregated view of the outside world on the performance of three of the algorithms described in section 4 . Each shows only a modest improvement. ${ }^{17}$

\footnotetext{
${ }^{16}$ Inputs purchased from other industries do not sum to one because of inputs in the forcing vector, $v$, such as labor.

${ }^{17}$ Although we do not pursue the effects of nonzero conjectures regarding $A_{22}$, note that guesses about row sums of $A_{22}$ are equivalent to overrelaxation acceleration of the feedback conjecture, $B$.
} 
Table 7: Effects of conjectured nonmember feedbacks.

\begin{tabular}{|c|c|c|c|c|c|}
\hline $\begin{array}{l}\text { Algorithm } \\
\text { used for } \\
\text { forming groups }\end{array}$ & $\begin{array}{l}\text { Number } \\
\text { of } \\
\text { groups }\end{array}$ & $\begin{array}{l}\text { Largest } \\
\text { group } \\
\text { size }\end{array}$ & $\begin{array}{c}\text { Average } \\
\text { mean lag } \\
\text { (AML) }\end{array}$ & $\begin{array}{c}\text { Average } \\
\text { communication } \\
\text { cost }(\mathrm{ACC})\end{array}$ & $\mathrm{AML}+\mathrm{ACC}$ \\
\hline Random-0.6 & 215 & 21 & 1.9151 & 0.0052 & 1.9203 \\
\hline \multicolumn{2}{|c|}{ w/ rest-of-world aggregation } & & 1.9047 & 0.0052 & 1.9099 \\
\hline 1-Largest-customer & 160 & 20 & 1.6739 & 0.0085 & 1.6824 \\
\hline \multicolumn{2}{|c|}{ w/ rest-of-world aggregation } & & 1.6623 & 0.0085 & 1.6708 \\
\hline 1-Largest-supplier & 52 & 74 & 1.4514 & 0.1069 & 1.5583 \\
\hline \multicolumn{2}{|c|}{ w/ rest-of-world aggregation } & & 1.4325 & 0.1069 & 1.5394 \\
\hline
\end{tabular}

\subsection{Effects of imperfect communication.}

In experiments thus far, we have assumed that communication between industries is always reliable and noiseless. We now relax that assumption, and specify that the communication of price information is stochastic. A new price will be communicated from one industry to another only with a fixed probability; if the price is not communicated, then the prospective recipient of the information will use its most recent available value instead. Thus, the recipient is never fed incorrect price information, merely outdated price information (with a nonzero probability).

Probabilistic communication represents several circumstances. First it reflects the effects of occasional "stale quotes", i.e., industries being forced to use outdated price estimates because of delays in transmitting price information. This could be due to imperfections in the mechanism for transmitting information, or due to "freeriders" in the group, hoping to take advantage of other industries' information disclosures, while not revealing their own. In a rough way, probabilistic communication may reflect also the effect of "menu costs". By this, we mean the phenomenon that industries may feel that the fixed expense of adjusting their prices exceeds the value to be gained by doing so. Refraining from small adjustments causes inaccurate price signals to be transmitted, and may impair the efficiency of the entire system. In our model there are no thresholds, but adding the element of randomization may suggest the general effect of industries failing to consistently transmit current price information.

We first consider the case when communication within groups is imperfect. Table 8 shows results on three of the algorithms from section 4 when each intragroup communication fails with probability 0.10 and 0.20 . All price information communicated between industries in different groups is transmitted accurately, though with a one period lag as before. 
Table 8: Imperfect communications within groups.

\begin{tabular}{|c|c|c|c|c|c|}
\hline $\begin{array}{l}\text { Algorithm } \\
\text { used for } \\
\text { forming groups }\end{array}$ & $\begin{array}{l}\text { Number } \\
\text { of } \\
\text { groups }\end{array}$ & $\begin{array}{l}\text { Largest } \\
\text { group } \\
\text { size }\end{array}$ & $\begin{array}{c}\text { Average } \\
\text { mean lag } \\
\text { (AML) }\end{array}$ & $\begin{array}{c}\text { Average } \\
\text { communication } \\
\text { cost }(\mathrm{ACC})\end{array}$ & $\mathrm{AML}+\mathrm{ACC}$ \\
\hline Random-0.6 & 215 & 21 & 1.9151 & 0.0052 & 1.9203 \\
\hline $90 \%$ reliability $^{a}$ & & & 2.0418 & 0.0052 & 2.0470 \\
\hline $80 \%$ reliability $^{a}$ & & & 2.2193 & 0.0052 & 2.2245 \\
\hline 1-Largest-customer & 160 & 20 & 1.6739 & 0.0085 & 1.6824 \\
\hline $90 \%$ reliability $^{a}$ & & & 1.7104 & 0.0085 & 1.7189 \\
\hline $80 \%$ reliability $^{a}$ & & & 1.7664 & 0.0085 & 1.7749 \\
\hline 1-Largest-supplier & 52 & 74 & 1.4514 & 0.1069 & 1.5583 \\
\hline $90 \%$ reliability $^{a}$ & & & 1.4607 & 0.1069 & 1.5676 \\
\hline $80 \%$ reliability $^{a}$ & & & 1.4749 & 0.1069 & 1.5817 \\
\hline
\end{tabular}

${ }^{a}$ Communication reliability within groups.

The performance degradations of stochastic intra-group communications are small (below $7 \%$ ) in every case except when random groups communicate with a $20 \%$ failure rate. Note that groups formed randomly suffer more from faulty intragroup communications than groups based on customer/supplier relationships. In the latter case, there is more interconnectivity among firms in the group and, thus, more opportunity for information missing due to transmission failures to be supplied from another source within the communication group.

Now, consider the reverse case of stochastic inter-group communications, introducing $10 \%$ and $20 \%$ error rates for transmissions between groups and restoring perfect communications within groups. The effects on the three algorithms appear in table 9. 
Table 9: Imperfect communications between groups.

\begin{tabular}{|c|c|c|c|c|c|}
\hline $\begin{array}{l}\text { Algorithm } \\
\text { used for } \\
\text { forming groups }\end{array}$ & $\begin{array}{l}\text { Number } \\
\text { of } \\
\text { groups }\end{array}$ & $\begin{array}{l}\text { Largest } \\
\text { group } \\
\text { size }\end{array}$ & $\begin{array}{c}\text { Average } \\
\text { mean lag } \\
\text { (AML) }\end{array}$ & $\begin{array}{c}\text { Average } \\
\text { communication } \\
\text { cost }(\mathrm{ACC})\end{array}$ & $\mathrm{AML}+\mathrm{ACC}$ \\
\hline Random-0.6 & 215 & 21 & 1.9151 & 0.0052 & 1.9203 \\
\hline $90 \%$ reliability $^{a}$ & & & 2.0931 & 0.0052 & 2.0982 \\
\hline $80 \%$ reliability ${ }^{a}$ & & & 2.4469 & 0.0052 & 2.4520 \\
\hline 1-Largest-customer & 160 & 20 & 1.6739 & 0.0085 & 1.6824 \\
\hline $90 \%$ reliability $^{a}$ & & & 1.8247 & 0.0085 & 1.8332 \\
\hline $80 \%$ reliability ${ }^{a}$ & & & 2.0227 & 0.0085 & 2.0312 \\
\hline 1-Largest-supplier & 52 & 74 & 1.4514 & 0.1069 & 1.5583 \\
\hline $90 \%$ reliability $^{a}$ & & & 1.5770 & 0.1069 & 1.6838 \\
\hline $80 \%$ reliability $^{a}$ & & & 1.7479 & 0.1069 & 1.8548 \\
\hline
\end{tabular}

${ }^{a}$ Communication reliability between groups.

Imperfect communications between groups is much more disruptive than faulty intragroup communications. At a 10\% failure rate, the performance degrades by $9 \%$ for each of the original three algorithms; when the rate is increased to $20 \%$, the performance is at least $20 \%$ worse than the case of perfect communications for all three of the algorithms. The reason that flawed communication among different groups is more problematic is probably that there are fewer opportunities for communicating prices between industries in different groups. Thus if an out-of-date price is transmitted, a longer period of time elapses before it will be updated. Consequently, more computations are performed using the inaccurate price information, and convergence to the optimal prices is delayed for longer intervals.

\subsection{Genetic algorithms.}

We also explored the use of genetic algorithms to find effective industry communication groups. A genetic algorithm is a randomized search procedure in which the goal is to "evolve" good algorithms through a process analogous to natural selection. A population of strings is maintained; each string represents a set of parameters that defines a particular algorithm. The genetic algorithm seeks to improve the performance of the strings in its population through successive generations. In each generation, the strings in the population are evaluated as to their performance on the 
problem at hand. Some of these strings are then selected randomly according to a probability distribution that weights good performers more heavily. The selected strings are then "bred" to form the next generation. "Breeding" is achieved by pairing off strings and having them exchange selected attributes; random mutations are also added to diversify the population. The resulting strings comprise the next generation. Genetic algorithms have been applied in a wide range of fields, including biology, operations research, integrated circuit design, and artificial intelligence. For an introduction to genetic algorithms see, for example, Goldberg (1989).

Due to the limited success we have thus far achieved using genetic algorithms, discussion will be brief. In order to apply genetic algorithms to the problem of finding good industry groupings, we designed a string encoding to represent a collection of groups. Each string is an array of 356 integers, where the $i$ th element of the array is the name of the group to which industry $i$ belongs. A pair of strings is "bred" by randomly choosing a position $p$ between 1 and 356. Each group is then split at $p$, and the pre- $p$ group fragments from the first string are spliced onto the post- $p$ fragments from the second string, and vice-versa. Operations of this type are typically known as crossovers in the genetic algorithms literature. ${ }^{18}$

Strings are also mutated by randomly splitting groups, and by randomly crossing over pairs of groups within a single string, by a process similar to that described above for pairs of strings. The probability of each of these operations being carried out is controlled by parameters supplied to the algorithm. We conducted tests of from 500 to 2500 generations, with population sizes varying from 20 to 40 .

Unfortunately, results thus far with genetic algorithms have not been very promising. The best performing string produced by such an algorithm has achieved a performance measure of only about 1.77 . While this is clearly better than randomly-selected groups, it does not approach the results of the better rule-of-thumb algorithms described earlier. The reason for this is almost certainly that we have not incorporated any domain knowledge into the genetic algorithm; it is essentially a random search. Since the search space of possible groupings is so huge, as noted earlier, algorithms that are not guided by heuristics that take into account the input-output structure of the $A$ matrix are unlikely to be successful.

\footnotetext{
${ }^{18}$ Note that this type of operation is very sensitive to the ordering of the information contained in the string, since adjacent string bits will almost never be separated, while bits far apart on the string will frequently be split up by crossovers. Thus, best results are likely to be achieved when the string can be encoded so that related attributes are positioned close together. We tried to achieve this by ordering the industries along the string so that an industry is close to its customers and suppliers, somewhat further from its suppliers' suppliers and its customers' customers, and quite distant from those industries with which it has virtually no contact. Unfortunately, our results improved very little even after this reordering.
} 


\section{References}

Ball, L. and G. Mankiw, "Asymmetric Price Adjustment and Economic Fluctuations," Economic Journal, 104, March 1994, 247-61.

Becker, G., "Irrational Behavior and Economic Theory," Journal of Political Economy, 70, 1, February 1962, 1-13.

Birchenhall, C., "MatClass: A Matrix Class for C++," Department of Econometrics and Social Statistics, University of Manchester, October, 1993.

Blanchard, O., "Aggregate and Individual Price Adjustment," Brookings Papers on Economic Activity, 1987, 57-109.

Blinder, A., "Why are Prices Sticky? Preliminary Results From an Interview Study," American Economic Review, 81, 2, May 1991, 89-96.

Caplin, A. and D. Spulbur, "Menu Costs and the Neutrality of Money," Quarterly Journal of Economics, 102, November 1987, 703-25.

Carlton, D., "The Rigidity of Prices," American Economic Review, September 1986, 637-58.

Domowitz, I., G. Hubbard, and B. Peterson, "Oligopoly Supergames: Some Empirical Evidence on Prices and Margins," The Journal of Industrial Economics, 35, 4, June 1987, 379-98.

Eckard, E., "Firm Market Share, Price Flexibility, and Imperfect Information," Economic Inquiry, 20, July 1982, 388-92.

Fisher, P., S. Holly, and A. Hughes-Hallett, "Efficient Solution Techniques for Dynamic Nonlinear Rational Expectations Models," Journal of Economic Dynamics and Control, 10, 1986, 139-45.

Garey, M. and D. Johnson, Computers and Intractability: A Guide to the Theory of NP-Completeness, New York: W. H. Freeman, 1979.

Geist, A., A. Beguelin, J. Dongarra, W. Jiang, R. Manchek, and V. Sunderam, "PVM 3.0 User's Guide and Reference Manual," Oak Ridge National Laboratory ORNL/TM-12187, February 1993.

Gilli, M. (ed.), Computational Economic Systems: Models, Methods \& Econometrics, Dordrecht: Kluwer Academic Publishers, 1996.

Gode, D. and S. Sunder, "Allocative Efficiency of Markets with Zero-Intelligence Traders: Market as a Partial Substitute for Individual Rationality," Journal of Political Economy, 101, 1, 1993, 119-37.

Goldberg, D., Genetic Algorithms in Search, Optimization, and Machine Learning, Reading, MA: Addison-Wesley, 1989.

Gordon, R., "Output Fluctuations and Gradual Price Adjustment," Journal of Economic Literature, 19, June 1981, 493-530.

Gordon, R., "What is New-Keynesian Economics?" Journal of Economic Literature, 28, September 1990, 1115-71. 
Green, E. and R. Porter, "Noncooperative Collusion under Imperfect Price Information," Econometrica, 52, January 1984, 87-100.

Greenwald, B. and J. Stiglitz, "Toward a Theory of Rigidities," American Economic Review, 79, 1989, 364-9.

Holland, J., Adaptation in Natural and Artificial Systems, Cambridge, MA: MIT edition, 1992.

Horn, R. and C. Johnson, Matrix Analysis, Cambridge: Cambridge University Press, 1985.

JáJá, J., An Introduction to Parallel Algorithms, Reading, MA: Addison-Wesley, 1992.

Karp, R., "Reducibility among Combinatorial Problems," R. Miller and J. Thatcher (eds.), Complexity of Computer Computations, New York: Plenum Press, 1972.

Keynes, J., The General Theory of Employment, Interest and Money, London: Macmillan, 1936.

Means, G., "Price Inflexibility and the Requirements of a Stabilizing Monetary Policy," Journal of the American Statistical Association, 1935, 401-13.

Mitchell, W., Business Cycles, Berkeley: University of California Press, 1913.

Perry, M., "Vertical Integration: Determinants and Effects," R. Schmalensee and R. Willig (eds.), Handbook of Industrial Organization, Vol. I, Amsterdam: North-Holland, 1989, 183-255.

Pigou, A., Industrial Fluctuations, London: Macmillan, 1927.

Qualls, D., "Market Structure and the Cyclical Flexibility of Price-Cost Margins," Journal of Business, 52, 2, April, 1979, 305-25.

Rotemberg, J., "Sticky Prices in the United States," Journal of Political Economy, 90, 6, December 1982, 1187-211.

Rotemberg, J. and G. Saloner, "A Supergame-Theoretic Model of Price Wars During Booms," American Economic Review, 76, 3, June, 1986, 390-407.

Sargent, T., "The Ends of Four Big Inflations," R. Hall (ed.), Inflation: Causes and Effects, Chicago: University of Chicago Press, 1982, 41-97.

Schmalensee, R., "Inter-Industry Studies of Structure and Performance," R. Schmalensee and R. Willig, (eds.) Handbook of Industrial Organization, Vol. II, Amsterdam: North-Holland, 1989, 951-1009.

Stoer, J. and R. Bulirsch, Introduction to Numerical Analysis, New York: Springer-Verlag, 1980.

Tinsley, P., "Fitting Both Data and Theories: Polynomial Adjustment Costs and Error-Correction Decision Rules," FEDS Working Paper 93-21, June 1993.

Tobin, J., "Inflation and Unemployment," American Economic Review, March 1972, 1-18.

Tsai, W., G. Huang, W. Lu, "Fast Parallel Recursive Aggregations Methods for Simulation of Dynamical Systems," IEEE Transactions on Automatic Control, 39, 3, March 1994, 534-40.

Tsiddon, D., "The (Mis)Behavior of the Aggregate Price Level," Review of Economic Studies, 60, 4, October 1993, 889-902. 
U.S. Department of Commerce, The 1982 Benchmark Input-Output Accounts of the United States, Washington, D.C.: US Government Printing Office, December 1991.

Vakhutinsky, I., L. Dudkin, and A. Ryvkin, "Iterative Aggregation - A New Approach to the Solution of Large-Scale Problems," Econometrica, 47, 4, July 1979, 821-41.

Varga, R., Matrix Iterative Analysis, Englewood Cliffs, NJ: Prentice-Hall, 1962.

Waterson, M., "Vertical Integration, Variable Proportions and Oligopoly," Economic Journal, 92, March 1982, 129-44. 